\title{
Pantries and policy implementation: \\ Using nonprofit priorities to understand variation in emergency food assistance
}

\author{
Rachel Fyall \\ Jamie Levine Daniel
}

\begin{abstract}
Governments have long-partnered with the nonprofit sector to carry out emergency food assistance, particularly through the use of nonprofit food pantries. While nonprofit pantries fill an important function in policy implementation, they also offer avenues for the charitable activities of their stakeholders, which may lead to substantial variation in the strategies, values, and priorities across organizations. Our research asks: To what extent is the level of food assistance provided by a pantry explained by variation in organizational priorities? Our analysis combines survey data from approximately 90 nonprofit food pantries associated with a Midwestern Foodbank with administrative records and community-level data. Findings indicate that the priorities of nonprofit pantries help explain variation in the levels of food assistance provided by pantries. This implies that policymakers may be better equipped to meet community food needs simply by knowing more about the organizational priorities of nonprofit service providers.
\end{abstract}

Key words: policy implementation, service delivery, organizational priorities, emergency food assistance, nonprofit pantry

This is the author's manuscript of the article published in final edited form as:

Fyall, R., \& Levine Daniel, J. (2018). Pantries and Policy Implementation: Using Nonprofit Priorities to Understand Variation in Emergency Food Assistance. Nonprofit and Voluntary Sector Quarterly, 47(4_suppl), 11S-33S. https://doi.org/10.1177/0899764017753318 


\section{Pantries and policy implementation:}

\section{Using nonprofit priorities to understand variation in emergency food assistance}

According to the United States Department of Agriculture (USDA), 12.7\% of all US households faced high levels of food insecurity in 2015, representing 29.1 million adults and 13.1 million children (Coleman-Jensen et al., 2016). These figures in and of themselves are notable, but do not tell the whole story. Demand for emergency food provision is not only increasing in poor communities that typically demand these services, but unexpected populations are also experiencing food insecurity, such as suburbs commonly thought to be well off (ColemanJensen, 2012) and college campuses (Gaines et al., 2014; Patton-Lopez et al., 2014).

Contemporaneously with this increase in demand, we have seen access to emergency food provision decrease. Federal programs like the Supplemental Nutrition Assistance Program (SNAP, formerly known as food stamps) are facing cuts and/or increased limitations on capacity (Algert, Reibel, \& Renvall, 2006; Berner \& O’Brien, 2004; Berner, Ozer, \& Paynter, 2008; Fusaro, 2015), thus increasing the importance of nonprofit food pantries as an essential aspect of the emergency food safety net. The Feeding America network includes 60,000 food pantries and meal programs throughout the United States, which is more than double the approximately 26,000 food pantries affiliated with the network (previously known as America's Second Harvest) in 2001 (Daponte \& Bade, 2006).

While the challenges of creating a census of nonprofit food pantries mirror the data challenges of the entire sector (Grønbjerg \& Clerkin, 2005), the variation amongst food pantries is well- 
documented. A recent study of a food pantry network in Northeast Florida characterized the diversity of food pantries as "ranging from small 'mom and pop' operations to pantries with multiple staff and volunteers who provide additional services such as thrift stores, clothes closets, referrals, and counselling services" (Will \& Milligan, 2015, p. 68). Pantries may be faithbased, faith-affiliated, or secular. Like any nonprofit organization, food pantries should be expected to differ in terms of specific mission, organizational priorities, emphasis on particular public values, and other dimensions (Frumkin, 2002).

Our study contrasts the variation in nonprofit food pantries with the essential policy role of pantries within the emergency food assistance system. Specifically, our research question asks: To what extent is the level of food assistance provided by a pantry explained by variation in organizational priorities? To address this question, we use administrative records from a Midwestern Foodbank serving a 20-county service area, a survey of approximately 90 nonprofit pantries associated with the Foodbank, and community-level data from the American Community Survey (ACS) and United States Department of Agriculture (USDA).

The paper begins with a brief overview of emergency food provision in the United States, drawing particular attention to joint public-nonprofit efforts. We then introduce the theoretical grounding for examining the role of nonprofits in shaping public service provision. This is followed by discussion of the six hypotheses motivating this research. We explain our data and methods before presenting the findings. We conclude with a discussion of the implications of the research findings as well as opportunities for future research that would potentially enhance the findings. 


\section{Historical Overview of Emergency Food Provision}

Federal and state governments have a long history of partnering with the nonprofit sector to carry-out policy priorities related to food provision. Through food and cash assistance, the government plays a major role in supplying regional food banks, which then distribute food through nonprofit pantries. Federal legislation also incentivizes related industries to donate surplus inventory to food banks. While churches and other nonprofit organizations offer the front-line service provision to hungry clients, decisions by public policymakers enable and ensure food assistance for those in need. This relationship represents what Young (2000) would consider a complementary government-nonprofit partnership.

Emergency food provision represents an intersection of public, private, and nonprofit efforts. Federal efforts in this policy arena date back to the mid-1930s. President Hoover established the Emergency Relief Administration (ERA) in 1932, which became the Federal Emergency Relief Administration (FERA) under President Franklin D. Roosevelt in 1935. While FERA's main focus was household unemployment, the program, along with other government agencies, became involved in formal food redistribution at this time. Congress began purchasing surplus agricultural products from farmers and redistributing surplus agricultural products to people in need. The first school lunch program was established in 1936, and the federal government began an experimental food stamp program from 1939-1943 that focused on vouchers for commodities.

Emergency food provision once again gained national attention in the 1960s, when John F. Kennedy made hunger a plank in his political platform. In 1964 the Food Stamp Act was 
established as a permanent government program. By the late 1960s, the nonprofit sector was making inroads in the delivery of this public service. John van Hengal established the world's first food bank in 1967, and the Field Foundation released Hunger, USA, which chronicled widespread malnutrition among America's poor. In response, the federal Select Committee on Nutrition and Human Needs was established, and Nixon declared a war on hunger in a 1969 address to Congress (Childs, 1969).

The next major era of food policy occurred in the 1970s. The 1970 Food Stamp Reform Bill mandated national standards of eligibility, and the special Supplemental Program for Women, Infants, and Children (WIC) was piloted in 1972. State governments also start to look to corporate actors to participate in emergency food provision. California passed the first Good Samaritan Food Donation Law in 1977, which limited corporate liability for food donations and therefore removed a substantial barrier for supplying food banks with private surplus food.

Emergency food provision in the 1980s came mostly from the federal government and the nonprofit sector. President Ronald Reagan cut the food stamp budget by $16 \%$ over 1981-1982, and simultaneously established the Emergency Food Assistance Program (TEFAP). This act guarantees USDA food assistance to emergency food provision for the first time. In 1982 the Electronic Benefits Transfer (EBT) program was piloted, and the Soup Kitchen-Food Bank (SKFB) Program was authorized to increase access to USDA commodities. 
The public, private, and nonprofit intersection of emergency food provision is highlighted in the 1990s. The Personal Responsibility and Work Opportunity Reconciliation Act (more commonly referred to as welfare reform) combines the TEFAP and SK-FB programs under one umbrella. In the same year, the federal government passes the Bill Emerson Good Samaritan Food Donation Act, protecting good faith food donors from civil and criminal liability at a national scale. Additionally, America's Second Harvest emerged as a national coordinator for food distribution.

Several trends dominated food provision in the 2000s. On the nonprofit side, America's Second Harvest reorganized as Feeding America, expanding its outreach. Some nonprofit organizations distributing food to hungry clients developed new methods of distribution such as a choice pantry, where clients can choose the products they need in a grocery store-like setting. Food pantries have also focused on just-in-time distribution for fresh produce. At the same time, changes in the private sector have affected the supply of surplus food. These include the emergency of secondary purchasers/resellers such as Big Lots, and improvements in just-in-time inventory practices.

This has shifted the balance in the relationship has changed over the past decade or so. Nonprofit organizations are increasingly called upon to fill the gaps in food safety net left by changes to public food assistance programs (Berner \& O’Brien, 2004; Berner, Ozer, \& Paynter, 2008) and barriers to food stamp access (Algert, Reibel, \& Renvall, 2006; Fusaro, 2015). This underscores the notion that nonprofit providers of emergency food services are essential components of the social safety net. Even as demand rises, though, the front-line emergency food providers such as 
food banks and food pantries have not been able to meet the demand (Nichols-Casebolt \& Morris, 2002).

\section{Nonprofits and Policy Implementation}

The shift to greater reliance on nonprofit food pantries within the emergency food system parallels a more general increase in delivering social services through nonprofit organizations. Both praise and criticism have accompanied the growth of publicly funded nonprofit social service provision. Government funding has fueled the growth of the nonprofit sector (Smith \& Grønbjerg, 2006), offering important financial opportunities for nonprofits (Gazley \& Brudney, 2007; Saidel, 1991). From the public perspective, nonprofit partners can offer advantages in terms of their community embeddedness and flexibility (Mulroy, 2003) as well as their potential for supplementing public resources with private donations and volunteer power (Brown, Potoski, \& Van Slyke, 2006).

On the other hand, the nonprofit sector has long been wary of the ways in which public support may undermine the sector's unique strengths (Smith \& Lipsky, 1993). Likewise, public management perspectives have cautioned that a lack of organizational capacity among nonprofit providers may impede the success of policy implementation through nonprofits (Fredericksen \& London, 2000; Poole et al., 2002). Overall, the nonprofit view of government support for nonprofit activities tends to evaluate the benefits and drawbacks with respect to nonprofit sector strength and autonomy. The public management view of public-nonprofit partnerships emphasizes organizational or structural advantages and liabilities. 
While ideology may guide preferences for providing services through particular sectors

(Thompson \& Elling, 2000), traditional policy implementation theories tend to privilege a goaloriented view of policy implementation (Sandfort \& Moulton, 2014); i.e., implementation choices should align with policy goals (Sabatier \& Mazmanian, 1979). In an ideal policy world, the scope and scale of policy problems would perfectly correspond to policy responses. For example, the provision of social services should follow trends in community need, such that social services are more plentiful in poor communities than in wealthy communities. The reality of policy implementation is obviously more complicated, but the assumption that policy implementation should prioritize policy goals is hardly controversial.

Bridging these perspectives, we argue that neither structural concerns nor the presumption of a policy goal orientation adequately represent the "nonprofit" component of policy implementation. Rather, nonprofit providers of public services are policy actors, shaping the social safety net in uniquely nonprofit ways (Author, 2016). Drawing from the management perspective, we acknowledge that capacity can influence the "success" of policy implementation, and we support a goal-oriented view that suggests a relationship between service levels and the characteristics of communities. However, our focus here is on the ways in which being a nonprofit agency shapes public service delivery. In particular, we examine the explanatory power of stated organizational priorities for understanding variation in food assistance by nonprofit pantries. Our perspective argues that the consideration of nonprofit organizational behavior is essential for understanding the landscape of emergency food provision in the U.S.

\section{The Uniqueness of Being Nonprofit}


To examine the relationship between nonprofit organizational priorities and service delivery levels, we draw upon decades of nonprofit scholarship investigating nonprofit organizational behavior. A nonprofit's mission can shape organizational identity, described as that which is “central, distinctive, and enduring" to an organization (Albert \& Whetten, 1985, p. 265). Organizational identity can be holographic, with each unit exhibiting parts of the whole, or fractured, reflecting split or specialized identities (Albert \& Whetten, 1985). This mirrors Ott's (1993) metaphor of a nonprofit organization as an atom, whereby the involvement and influence of nonprofit stakeholders can vary throughout the organization's history. A nonprofit can hold many values simultaneously, but a prioritization of values may be revealed through organizational activities, including service delivery.

Nonprofits provide public goods and services, but they also carry out mission-related activities that span a variety of roles in their communities, including innovation, social capital creation, citizen engagement, political advocacy, and value expression (Kim, 2016; Moulton \& Eckerd, 2012). Frumkin (2002) discusses two dimensions along which to consider mission and organizational priorities: supply or demand orientation, and instrumental or expressive rationale. The key assumption for this research is that pantries are not just passively doling out food assistance. How organizations perceive their mission, and, therefore, prioritize their activities, may be evidence of a fractured organizational identity, and result in practices that do not maximize service delivery or larger policy goals. In the case of food pantries, the policy goal concerns reducing food insecurity or meeting emergency hunger needs. Therefore, we expect the following: 


\section{H1: Pantries that prioritize meeting the hunger needs of their communities will}

provide a higher service level than those that do not.

Nonprofit organizations need to address the needs of multiple stakeholders in order to be sustainable (Freeman, 1984; Fassin, 2009). Food pantries serve as the street-level bureaucracy of food policy while also offering an avenue for the charitable activities of volunteers and concerned community members. Often, these organizations are located within houses of worship. Though the pantries are not, themselves, religious congregations, they may focus beyond what Frumkin (2002) considers instrumental and demand-driven, prioritizing the expression of stakeholder values as part of their practices. Therefore, service levels may be lower if the expression of non-client stakeholder values takes priority over the needs or demands of clients. H2: Pantries that prioritize the faith/values expression of their staff, volunteers, and donors will provide a lower service level than those that do not.

That said, the strength of a particular stakeholder's value set is unknown, and may depend on which stakeholder group the pantry prioritizes. For example, the prioritization of the values expression of staff and volunteers may lead to increased service delivery, since staff and/or volunteers who work on the front lines and have repeated engagement with clients have an opportunity to build trust (Powell, 1996). However, frontline service providers also have the opportunity to exercise discretion in ways that can reward "worthy" clients with augmented services while discouraging or withholding services from clients deemed undeserving (MaynardMoody \& Musheno, 2000). Similarly, the prioritization of donors' values expression may bolster 
or undercut service levels, depending on the preferences of the individuals involved. Therefore, we expect the following:

H2a: We expect some relationship between pantries that prioritize faith/values expression of staff/volunteers and service delivery, but the direction is unclear.

H2b: We expect some relationship between pantries that prioritize faith/values expression of donors and service delivery, but the direction is unclear.

A pantry's approach to service delivery can also reflect organizational priorities. Nonprofits have experienced demands to embrace "business-like" practices (Dart, 2004), which is often associated with a focus on efficiency. The "marketization" of nonprofits has its deterrents (Eikenberry \& Kluver, 2004), but organizations prioritizing cost efficiency may provide a higher volume of services than those unconcerned with market values.

H3: Pantries that prioritize cost efficient services will provide higher service levels than those that do not.

Relatedly, the nonprofit form may foster innovation and experimentation thanks to low barriers to starting a nonprofit and the freedom to operate independent of a strict profit model (RoseAckerman, 1996). Networking and collaboration may provide opportunities to learn about new service strategies or pursue goals beyond those defined by the organization's mission (Suárez, 2011). Pantries affirming these priorities may be able to offer higher levels of service than those that do not. 
H4: Pantries that prioritize developing and sharing new service strategies will provide higher service levels than those that do not.

Conversely, a focus on the quality of services may involve a trade-off with service levels, attributable to an increase in the cost of service delivery (Weisbrod, 1991). An economic perspective on nonprofit form anticipates that nonprofits are likely to prioritize high-quality services, even while recognizing that this can affect cost and, therefore, service levels (Newhouse, 1970).

H5: Pantries that prioritize providing high-quality services will provide lower service levels than those that do not.

Lastly, some nonprofits are inclined to welcome their role as policy actors, actively pursuing opportunities for public sector engagement (Fyall, 2016) and serving as dutiful stewards of public policy (Van Slyke, 2007). In her study of local government-nonprofit collaborative activity in Georgia, Gazley (2010) finds that the intensity of shared goals and the level of investment in the partnership are related to perceptions of improved organizational performance. We can therefore expect nonprofits who actively embrace this role as actors in some capacity to demonstrate alignment with government goals of meeting community need:

H6: Pantries involved in government-partnering or public sector engagement will provide higher service levels than those that do not.

\section{Data and Methods}


To evaluate our hypotheses, this research relies on data from four different sources: administrative data from a Foodbank, a survey of nonprofit food pantries associated with the Foodbank, the 2010-2014 American Community Survey, and the Food and Nutrition Service of the USDA. All measures, data sources, and summary statistics are displayed in Table 1 and discussed in more detail below.

***Table 1 about here***

The core research question investigates the extent to which organizational priorities are associated with varying levels of service. We operationalize service level as the total number of individuals served by each pantry in 2010, a measure obtained from the Foodbank's administrative records. In accordance with Foodbank tracking standards, this measure refers to the sum of individuals served per day over the course of the year. In other words, an individual who visits a food pantry once per month would be counted as 12 individuals served by that pantry. To assist in interpretation of the results, we used the natural log of this measure in the analyses.

The key independent variables associated with organizational priorities are drawn from a survey of nonprofit pantries. The surveyed pantries are affiliates of a single Foodbank that serves as the primary distributor for an emergency food distribution network in central and eastern Ohio. The Foodbank currently has more than 650 partner agencies across 20 counties, such as food pantries, soup kitchens, shelters, and after school programs. The Foodbank's food sources include the 
USDA, food manufacturers, local agriculture producers, nonprofits, and businesses, enabling the provision of nearly 150,000 meals daily.

The survey was conducted as a component of a larger research project in collaboration with the Foodbank. ${ }^{1}$ Survey questions were informed by eight regional focus groups with pantries conducted in March-May 2010. At the time of the survey, nonprofit pantries comprised 270 of the Foodbanks partner agencies. In June 2010, an online survey was email to executive directors or primary contacts of these 270 nonprofit pantries. Non-respondents received follow-up through email, postal mail, and telephone, including an option to complete the survey via telephone. Representatives from 148 nonprofit pantries (55\%) responded to the survey, yielding 95 usable responses $(35 \%)$ for the purposes of this research.

The measures associated with organizational priorities were drawn from a list of potential priorities introduced with the following prompt: "Despite performing similar services, different food pantries have different values and purposes. Please indicate how much you think the following values and purposes represent your food pantry on the following scale, with 1 being 'does not represent our values/purpose' and 5 being 'strongly represents our values/purposes." The survey then lists 21 different phrases associated with organizational priorities, values, and/or purposes. We selected from among these 21 phrases based on theoretical grounding and sufficient variation in responses. Table 2 provides the complete wording for each phrase as well as the shorthand used throughout the manuscript.

***Table 2 about here $* * *$ 
Although the survey asks respondents to rate each phrase on a 5-point scale, we transformed these responses into dichotomous measures indicating whether or not the respondent selected "5" (i.e., "strongly represents our values/purposes"). While we recognize that organizations may hold many values simultaneously, we assume those values or priorities that "strongly represent" an organization have the highest expectation of influencing organizational behavior. ${ }^{2}$ Thus, the measures used here are dichotomous variables where a " 1 " indicates that the phrase "strongly represents" the pantry's priorities.

We also used the survey values questions to construct two priority-related variables. The dichotomous measure "Vehicle for staff, volunteers, and donors to express their faith" is an interaction term between the two faith/values-expression variables, indicating whether or not the respondent stated that pantry is strongly represented by the faith/values expression of staff and volunteers in addition to the faith/values expression of donors. The measure "Governmentpartnering or public sector engagement" is a count variable (possible values range 1-8) comprised of the associated phrases listed in Table 2. Consistent with other measures, this measure only considers whether or not a pantry selected "strongly represents" for each phrase.

In addition to information about organizational priorities, the survey provides details about pantry capacity. Survey respondents indicated whether or not their pantry at the capacity to serve additional clients, which we include as a measure of perceived additional capacity. Survey respondents also provided information about types of assistance beyond food provision that may be provided by the pantry, such as rental assistance, shelter, immigrant services, or childcare. We 
include a dichotomous measure indicating whether or not the pantry provides any non-food social service. Based on Foodbank records, we include a dichotomous variable indicating whether or not the pantry has any paid staff.

To incorporate an understanding for the level of emergency food assistance needed across the pantries' service area, we geocoded each pantry in order to match each pantry with census tractlevel demographic variables from the American Community Survey (2010-2014). Since no direct measures of hunger or food insecurity are publicly available at the census tract level, we include measures for median household income and the number of female headed-households in the census tract. Previous research has shown these measures to be the most important predictors of food insecurity (Furness et al., 2004; Nord et al., 2010).

Finally, to accommodate differences in the provider environment and availability of food assistance for low-income individuals and households, we used data from the Food and Nutrition Service of the USDA to compile a count of SNAP retailers within each food pantry's census tract. We augmented this count with the number of known food pantries also in the census tract to create a combined measure of SNAP providers and pantries by census tract. Our analysis uses Ordinary Least Squares regression. All models cluster standard errors by food pantry county.

\section{Findings}

Table 3 models the individuals served by each pantry as a function of measures of organizational priorities, organizational capacity, and community need. The three models presented differ on 
the inclusion of different measures concerning the value or faith expression of pantry stakeholders. The following discussion interprets the findings in light of the six hypotheses.

$* * *$ Table 3 about here***

Hypothesis 1 predicts that pantries prioritizing meeting the hunger needs of their communities will provide a higher service level than those that do not. Not surprisingly, more than three quarters of surveyed pantries reported this concept as an organizational value. Regressing results in all three models indicate that even after controlling for organizational capacity and community-level characteristics, this priority was associated with nearly $50 \%$ increase in the number of individuals served by a pantry as compared to the pantries that do not state this as a priority. The analysis supports Hypothesis 1.

Drawing on Frumkin's (2002) supply-side approach, Hypothesis 2 posits that pantries that prioritize the faith or values expression of staff, volunteers, and donors are likely to provide lower service levels than pantries that do not identify with the values expression of these nonclient stakeholders. In Model A, we model the faith or values expression jointly, considering only whether or not each pantry prioritizes the values of all three stakeholder groups (staff, volunteers, and donors). Model A results indicate that the joint values do not help explain variation in service levels. ${ }^{3}$

Model B uses the faith/values measures that parallel the survey questions. In separating the values expression of staff and volunteers, who likely have more front-line engagement with 
clients, from the values expression of donors, results indicate that both types of values expression relate to the number of individuals served, but they operate in opposing directions. In Model B, prioritizing the pantry as a vehicle for staff and volunteers to express their faith or values is associated with a nearly $40 \%$ increase in service levels compared to pantries that do not prioritize the values expression of these stakeholders. Conversely, pantries that prioritize the pantry as a vehicle for donors to express their faith are associated with a $56 \%$ decrease in service levels compared to other pantries.

Model C incorporates all three faith/values measures, thereby mimicking a categorical variable where the omitted category is pantries that prioritize neither the values expression of staff and volunteers nor the values expression of donors. This model intensifies the findings from Model B regarding the values expression of donors, associating this priority with a more than $75 \%$ decrease in individuals served. However, Model C fails to find a statistically significant relationship between service levels and the other two faith/values measures. Collectively, the models indicate that the relationship between service levels and the values expression of nonclient stakeholders is driven by those pantries that prioritize the faith or values expression of donors but not the values expression of staff and volunteers. Thus, Hypothesis 2 is not supported overall, but the relationship examined through Hypothesis $2 \mathrm{~B}$ is found to be negative.

Hypothesis 3 predicts a positive association between the prioritization of cost efficiency and service levels. All three models support this hypothesis, with a cost efficiency priority associated with an increase of approximately 50\% in individuals served, on average, across all three models. All three models also support Hypothesis 4, which predicts that pantries that prioritize 
developing and sharing new service strategies will provide higher service levels than those that do not. Prioritizing the development and sharing of new service strategies is associated, on average, with a nearly $75 \%$ increase in service levels.

Consistent with a commonly-assumed trade-off between quality and quantity, Hypothesis 5 predicts a negative relationship between pantries that prioritize high-quality programs and the number of individuals served. In fact, regression results do not indicate a statistically significant relationship between this priority and service levels. Hypothesis 5 is not supported.

Finally, Hypothesis 6 considers the prioritization of government-partnering or public sector engagement, predicting that this priority will be positively associated with service levels. The models indicate that these priorities are related to service levels, accounting for, on average, a $20 \%$ increase in the number of individuals served. These results support Hypothesis 6 . Table 4 displays a summary of the hypotheses and the associated findings.

$* * *$ Table 4 about here $* * *$

In addition to the hypotheses-related findings, the results regarding the capacity measures and community characteristics are also instructive. Of the variables related to organizational capacity, the presence of paid staff has a statistically significant relationship with service levels, confirming Eisinger's (2002) findings that professionalization is associated with effectiveness towards "try[ing] to help the hungry get food" (p. 118). On average across all three models, a pantry having paid staff is associated with an over $80 \%$ increase in the number of individuals 
served. It is worth noting that the magnitude of this relationship surpasses the magnitude of any of the priority-related measures.

With regard to community characteristics, median household income is negatively associated with service levels, while the number of female-headed households in the pantry's census tract is positively associated with service levels. These results confirm some alignment between pantry food provision and policy priorities, indicating that, holding other factors constant, higher levels of community need are associated with a greater number of individuals served. On the other hand, the results show no relationship between pantries' service levels and the local service environment, as operationalized by the total number of SNAP retailers and known pantries within a pantry's census tract.

As a robustness check, we also estimated three models (not shown) corresponding to Models A, $\mathrm{B}$, and $\mathrm{C}$ that incorporated two additional measures regarding the strategic decisions of the pantry. Knowing that the organizational priorities of the pantry may be expressed through strategic decisions, and the selected strategies may systematically influence service levels, we wanted to confirm that it was the priorities themselves—not the resulting service approachesthat are associated with service levels. The two additional measures we considered were a) the presence of limits on how many times an individual can receive food assistance from a pantry during a given month (operationalized as strict limits, flexible limits, or no limits), and b) the choice status of the pantry. ${ }^{4}$ Choice status refers to the degree to which clients can choose the food items they receive (operationalized as full choice, partial choice, no choice but would like to be, and no choice with no interest in becoming a choice pantry). The inclusion of these 
variables did not substantively change any of the results previously discussed, nor did they provide additional insight into variation across pantry service levels.

\section{Discussion, implications, and conclusion}

Nonprofit pantries are a fundamental component of the emergency food service system in the United States. A policy perspective might assume that nonprofit pantries are primarily driven by a desire to meet community hunger needs, yet decades of nonprofit scholarship predicts substantial variation in the organizational priorities and behaviors of nonprofits. Seeking to bridge the two perspectives, this research investigates the extent to which the level of food assistance provided by a pantry is explained by variation in organizational priorities.

Overall, the results showcase five different organizational priorities that have a statistically significant relationship with the number of individuals served by a food pantry, even after considering organizational capacity and community characteristics. These results have substantive significance as well, with the relationship of the smallest magnitude (pantries prioritizing government-partnering or civic engagement activities) associated with a $20 \%$ increase in the number of individuals served. For the average pantry in our survey (serving more than 35,000 individuals annually), this accounts for an additional 7,000 individuals served. ${ }^{5}$ The priority with the largest magnitude (developing and sharing new service strategies) accounts for, on average, nearly 26,000 additional individuals served by the average pantry in a given year. The findings clearly support the theory that organizational priorities shape service delivery. 
The relationships (or lack thereof) regarding specific priorities contribute to our understanding of particular aspects of nonprofit behavior. Perhaps the most interesting aspect of Hypothesis 1 is that nearly $25 \%$ of the survey respondents did not indicate that "meeting the hunger needs in our community" "strongly represents" the values and purposes of their food pantry. A closer look at these pantries revealed no obvious patterns regarding geography, size, or responses to the other organizational priority phrases. This potentially contrasts with the federal understanding of pantries, which defines "food pantry" as "a public or private nonprofit organization that distributes food to low-income and unemployed households, including food from sources other than the Department of Agriculture, to relieve situations of emergency and distress" (The Emergency Food Assistance Program, 1986).

Revisiting the original survey responses, most (but not all) of these respondents indicated that "meeting the hunger needs in our community" "mostly represents" their pantry's values or purpose, yet their responses typically indicated at least one other priority as "strongly representing" their pantry. Policymakers assuming that nonprofit service providers operate under a demand-side orientation (Frumkin, 2002) or as stewards of government (Van Slyke, 2007) may wish to reexamine this assumption.

The results concerning the faith or values expression of non-client stakeholders underscores this point. Pantries that interpret a component of their purpose as "providing a vehicle for private donors to express their values and/or faith through our programs/services"-while not simultaneously prioritizing the pantry as a vehicle for the faith or values expression of staff and 
volunteers - provide, on average, substantially lower levels of service provision than pantries without this prioritization set.

This finding should not be interpreted as a caution against government partnering with faithbased pantries: Over $85 \%$ of our sample has a religious affiliation, and not all of the pantries driving this trend have a faith affiliation. Rather, this finding exemplifies the ways in which organizational priorities are unique to each nonprofit, and broad assumptions about nonprofit behavior based on easily-measurable characteristics are not likely to capture these nuances.

The positive associations between service levels and priorities related to cost efficiency, developing and sharing new strategies, and government-partnering and civic engagement are unsurprising given their likely alignment with policy goals. Each of these priorities conveys an understanding of the pantry as more than just a point of pass-through services or personal charitable opportunity. These priorities contrast with the nonprofit tendency toward amateurism (Salamon, 1995). Combined with the importance of the presence of paid staff, this aspect of the findings supports the notion that professionalization and formalization are associated with an increasingly instrumental orientation (Hwang \& Powell, 2009). While others lament this as a potential loss for the sector (Eikenberry \& Kluver, 2004; Smith \& Lipsky, 1993), policymakers seeking to maximize the connection between need and service provision may find this encouraging. In an environment where government actors have the opportunity to choose among nonprofit partners, simply asking about organizational priorities may help improve policy outcomes. 
This research provides empirical evidence for the importance of nonprofit priorities to the emergency food service network, yet a number of limitations must be acknowledged. Our sample size is small and geographically concentrated. Since all organizations are part of the same Foodbank network, we may be capturing unknown effects unique to this network, making our results not generalizable outside this network. Another consideration is the potential for selection effect among survey respondents, who may systematically differ from non-respondents.

The small sample also limited the sample of organizational priorities we could consider, since some priorities yielded insufficient cell size for analysis. In spite of this limitation, we incorporated the government-partnering priority using a composite nature, though these priorities may have more meaning in isolation. Some of these priorities, such as participating in commissions or attempting to influence policy, may intuitively relate to each other and to service delivery. However, others may not fit together or may have a negative relationship with service levels. This limitation is a starting point that offers future opportunities for deeper analysis.

Nonprofit food pantries serve an important function in the implementation of emergency food policy, and their role is likely to grow if national trends in food insecurity continue. Policymakers and public managers seeking to foster a social safety net responsive to community needs should understand that pantry priorities relate to service levels, even after taking into consideration organizational capacity, strategic choices, community demand, and the local service environment. This research indicates that simply knowing more about the organizational priorities of nonprofit service providers could help policymakers better understand and plan for variation attributable to service provider outcomes. 


\section{Notes}

1. We have temporarily omitted additional details about the origin of the survey in order to avoid compromising the double-blind peer review process.

2. Our data cleaning efforts, in which we reconciled duplicate responses from five pantries, also informed this measurement choice. There was greater alignment across duplicate responses when respondents indicated a value as strongly representing the pantry as compared to other responses.

3. This result is consistent with modeling the prioritization of the faith/values expression as a marginal frequency (results not shown), considering if the pantry prioritizes the faith/values expression staff and volunteers or donors.

4. The survey collected this information.

5. While this represents an appropriate interpretation of the average effect of each additional government-partnering/civic engagement priority, this measure is constructed as a count, whereas the other priority measures are dichotomous. 


\section{References}

Albert, S., \& Whetten, D.A. (1985). Organizational identity. Research in Organizational Behavior, 7, 263-295.

Algert, S. J., Reibel, M., \& Renvall, M. J. (2006). Barriers to participation in the food stamp program among food pantry clients in Los Angeles. American journal of public health, 96(5), 807-809.

Berner, M., \& O'Brien, K. (2004). The shifting pattern of food security support: food stamp and food bank usage in North Carolina. Nonprofit and voluntary sector quarterly, 33(4), 655-672.

Berner, M., Ozer, T., \& Paynter, S. (2008). A portrait of hunger, the social safety net, and the working poor. Policy Studies Journal, 36(3), 403-420.

Brown, T., Potoski, M., \& Van Slyke, D. (2006). Managing Public Service Contracts: Aligning Values, Institutions, and Markets. Public Administration Review, 66(3), 323-331.

Childs, M. (1969, Feb. 11). Nixon's war on hunger involves cracking the system of scarcity. The Morning Record. Retrieved from https://news.google.com/newspapers?nid=vq25oHwZT$8 \mathrm{C} \&$ dat $=19690211 \&$ printsec $=$ frontpage $\&$ hl $=$ en.

Coleman-Jensen, A. (2012). Predictors of US food insecurity across nonmetropolitan, suburban, and principal city residence during the great recession. Journal of Poverty, 16(4), 392-411.

Coleman-Jensen, A., Rabbitt, M. P., Gregory, C. A., \& Singh, A. (2016). Household Food Security in the United States in 2015. US Department of Agriculture ed, 141.

Daponte, B. O., \& Bade, S. (2006). How the private food assistance network evolved: Interactions between public and private responses to hunger. Nonprofit and Voluntary Sector Quarterly, 35(4), 668-690.

Dart, R. (2004). Being "Business-Like" in a Nonprofit Organization: A Grounded and Inductive Typology. Nonprofit and Voluntary Sector Quarterly, 33(2), 290-310.

Eikenberry, A. M., \& Kluver, J. D. (2004). The marketization of the nonprofit sector: civil society at risk?. Public administration review, 64(2), 132-140.

Eisinger, P. (2002). Organizational capacity and organizational effectiveness among street-level food assistance programs. Nonprofit and Voluntary Sector Quarterly, 31(1), 115-130.

The Emergency Food Assistance Program, 51 Fed. Reg. 12823 (April 16, 1986).

Fassin, Y. (2009). The stakeholder model refined. Journal of Business Ethics, 84(1), 113-13.

Fredericksen, P., \& London, R. (2000). Disconnect in the Hollow State: The Pivotal Role of Organizational Capacity in Community-Based Development Organizations. Public Administration Review, 60(3), 230-239. 
Freeman, R. E. (1994). The politics of stakeholder theory: Some future directions. Business Ethics Quarterly, 4(4): 409-421.

Frumkin, P. (2002). On being nonprofit: A conceptual and policy primer. Harvard University Press.

Furness, B. W., Simon, P. A., Wold, C. M., \& Asarian-Anderson, J. (2004). Prevalence and predictors of food insecurity among low-income households in Los Angeles County. Public health nutrition 7(06), 791-794.

Fusaro, V. A. (2015). Who's Left Out: Characteristics of Households in Economic Need Not Receiving Public Support. Journal of Sociology \& Social Welfare, 42, 65.

Fyall, R. (2016). The Power of Nonprofits: Mechanisms for Nonprofit Policy Influence. Public Administration Review, 76(6), 938-948.

Gaines, A., Robb, C. A., Knol, L. L., \& Sickler, S. (2014). Examining the role of financial factors, resources and skills in predicting food security status among college students. International Journal of Consumer Studies, 38(4), 374-384.

Gazley, B. (2010). Linking Collaborative Capacity to Performance Measurement in Government-Nonprofit Partnerships. Nonprofit and Voluntary Sector Quarterly, 39(4), 653673.

Gazley, B., \& Brudney, J. L. (2007). The Purpose (and Perils) of Government-Nonprofit Partnerships. Nonprofit and Voluntary Sector Quarterly, 36(3), 389-415.

Grønbjerg, K. A. and Clerkin, R. M. (2005). Examining the landscape of Indiana's nonprofit sector: Does what you know depend on where you look? Nonprofit and Voluntary Sector Quarterly, 34(2), 232-259.

Hwang, H., \& Powell, W. W. (2009). The Rationalization of Charity: The Influences of Professionalism in the Nonprofit Sector. Administrative Science Quarterly, 54(2), 268-298.

Kim, M. (2016). Characteristics of Civically Engaged Nonprofit Arts Organizations: The Results of a National Survey. Nonprofit and Voluntary Sector Quarterly, 0899764016646473.

Maynard-Moody, S., \& Musheno, M. (2000). State Agent or Citizen Agent: Two Narratives of Discretion. Journal of Public Administration Research and Theory: J-PART, 10(2), 329-358.

Moulton, S., \& Eckerd, A. (2012). Preserving the publicness of the nonprofit sector resources, roles, and public values. Nonprofit and Voluntary Sector Quarterly, 41(4), 656-685.

Mulroy, E. A. (2003). Community as a Factor in Implementing Interorganizational Partnerships: Issues, Constraints, and Adaptations. Nonprofit Management \& Leadership, 14(1), 47-66.

Newhouse, J. P. (1970). Toward a theory of nonprofit institutions: An economic model of a hospital. The American Economic Review, 60(1), 64-74.

Nichols-Casebolt, A., \& Morris, P. M. (2002). Making ends meet: Private food assistance and the working poor. Journal of Social Service Research, 28(4), 1-22. 
Nord, M., Coleman-Jensen, A., Andrews, M., \& Carlson, S. (2010). Household Food Security in the United States, 2009. ERR-108, U.S. Dept. of Agriculture, Econ. Res. Serv. November.

Ott, J. S. (1993). Perspectives on organizational governance: some effects on governmentnonprofit relations. Southeastern Political Review, 21(1), 3-21.

Patton-López, M. M., López-Cevallos, D. F., Cancel-Tirado, D. I., \& Vazquez, L. (2014). Prevalence and correlates of food insecurity among students attending a midsize rural university in Oregon. Journal of nutrition education and behavior, 46(3), 209-214.

Poole, D., Ferguson, M., DiNitto, D., \& Schwab, A. (2002). The Capacity of Community-Based Organizations to Lead Local Innovations in Welfare Reform: Early Findings from Texas.

Nonprofit Management and Leadership, 12(3), 261-276.

Powell, W. W. (1996). Trust-based forms of governance. In R. M. Kramer \& R. Tyler (Eds.), Trust in organizations: Frontiers of theory and research (pp. 51-67). Thousand Oaks, CA: Sage.

Rose-Ackerman, S. (1996). Altruism, nonprofits, and economic theory. Journal of economic literature, 34(2), 701-728.

Sabatier, P., \& Mazmanian, D. (1979). The Conditions of Effective Implementation: A Guide to Accomplishing Policy Objectives. Policy Analysis, 5(4), 481-504.

Saidel, J. R. (1991). Resource interdependence: The relationship between state agencies and nonprofit organizations. Public Administration Review, 543-553.

Salamon, L. M. (1995). Partners in Public Service: Government-Nonprofit Relations in the Modern Welfare State. Baltimore, MD: The Johns Hopkins University Press.

Sandfort, J., \& Moulton, S. (2014). Effective Implementation in Practice Integrating Public Policy and Management. Hoboken, N.J.: Wiley.

Smith, S. R., \& Grønbjerg, K. A. (2006). Scope and theory of government-nonprofit relations. The Nonprofit Sector: A Research Handbook, 221-242.

Smith, S. R., \& Lipsky, M. (1993). Nonprofits for hire: The welfare state in the age of contracting. Cambridge: Harvard University Press.

Suárez, D. F. (2011). Collaboration and professionalization: The contours of public sector funding for nonprofit organizations. Journal of Public Administration Research and Theory, 21(2), 307-326.

Thompson, L., \& Elling, R. (2000). Mapping Patterns of Support for Privatization in the Mass Public: The Case of Michigan. Public Administration Review, 60(4), 338-348.

Van Slyke, D. M. (2007). Agents or stewards: Using theory to understand the governmentnonprofit social service contracting relationship. Journal of Public Administration Research and Theory, 17(2), 157-187. 
Weisbrod, B. A. (1991). The health care quadrilemma: an essay on technological change, insurance, quality of care, and cost containment. Journal of economic literature, 29(2), 523-552.

Will, J. A., \& Milligan, T. A. (2015). Toward an understanding of food pantry food recipients and the agencies that serve them. Journal of Applied Social Science, 9(1), 65-74.

Young, D. R. (2000). Alternative models of government-nonprofit sector relations: Theoretical and international perspectives. Nonprofit and voluntary sector quarterly, 29(1), 149-172. 
Table 1. Measures, data sources, and summary statistics

\begin{tabular}{|c|c|c|c|c|}
\hline Measure & Data source & Mean & $\begin{array}{c}\text { Std. } \\
\text { deviation }\end{array}$ & Obs. \\
\hline \multicolumn{5}{|l|}{ Dependent variable: Service level } \\
\hline Individuals served in 2010 & Foodbank & 35,443 & 41,679 & 88 \\
\hline \multicolumn{5}{|l|}{ Organizational priorities } \\
\hline Meeting community hunger needs & Pantry survey & .768 & .242 & 95 \\
\hline Vehicle for staff, volunteers, and donors to express their faith & Pantry survey & .242 & .431 & 95 \\
\hline Vehicle for staff and volunteers to express their faith & Pantry survey & .432 & .498 & 95 \\
\hline Vehicle for donors to express their faith & Pantry survey & .337 & .475 & 95 \\
\hline Providing cost efficient services & Pantry survey & .326 & .471 & 95 \\
\hline Developing and sharing new service strategies & Pantry survey & .168 & .376 & 95 \\
\hline Providing high quality services & Pantry survey & .421 & .496 & 95 \\
\hline Government-partnering or public sector engagement (count 1-8) & Pantry survey & .747 & 1.368 & 95 \\
\hline \multicolumn{5}{|l|}{ Organizational capacity } \\
\hline Paid staff & Foodbank & .283 & .453 & 92 \\
\hline Perceived capacity to serve additional clients & Pantry survey & .553 & .500 & 94 \\
\hline Provide non-food social services & Pantry survey & .516 & .502 & 95 \\
\hline \multicolumn{5}{|l|}{ Community characteristics } \\
\hline Median household income & ACS 2010-2014 & 44,073 & 18,725 & 95 \\
\hline \# of female headed households & ACS 2010-2014 & 223.43 & 175.91 & 95 \\
\hline \# of SNAP providers and pantries & USDA, pantry survey & 5.537 & 3.035 & 95 \\
\hline
\end{tabular}


Table 2. Survey wording for organizational priority measures

Measure name
Meeting community hunger needs
Vehicle for staff and volunteers to express their faith

Vehicle for donors to express their faith

Providing cost efficient services

Developing and sharing new service strategies

Providing high quality services

Associated survey wording

Meeting the hunger needs in our community

Providing an opportunity for volunteers and staff to express their faith and/or values in service to the community (personal ministry opportunity)

Providing a vehicle for private donors (of money or food) to express their values and/or faith through our programs/services

Providing cost efficient programs/services

Developing new strategies to provide services, and sharing them with other food pantries

Providing high quality programs/services to individuals

Participating in or promoting voter education and voter participation

Community organizing around social issues

Participating in government committees or commissions

Meeting with public officials, elected or appointed, staff, providing testimony on policy issues

Government-partnering or public sector engagement (count measure based on the corresponding phrases)
Participating in or promoting public education campaigns (e.g.: about ending hunger)

Participating in coalitions with other organizations for the purpose of influencing policy

Participating in or promoting census participation

Working with community leaders to address and advocate for hunger relief programs in our area 
Table 3. OLS regression models of nonprofit pantries' organizational priorities, organizational capacity, and community characteristics on individuals served (In)

\section{Organizational priorities}

Meeting community hunger needs

Vehicle for staff, volunteers, and donors to express their faith

Vehicle for staff and volunteers to express their faith

Vehicle for donors to express their faith

Providing cost efficient services

Developing and sharing new service strategies

Providing high quality services

Government-partnering or public sector engagement (count 1-8)

\section{Organizational capacity}

Paid staff

Perceived capacity to serve additional clients

Provide non-food social services

\section{Community characteristics}

Median household income (in thousands)

\# of female headed households

\# of SNAP providers and pantries

Constant

Constant

$\mathrm{N}=85$

t

A

$$
.540^{* *}
$$

B

$.439^{* *}$
$(.139)$

$.462^{* *}$

.336

(.427)

$.390^{* *}$

$(.109)$

.278

(.239)

$-.562^{* *}$

(.137)

$-.765^{* *}$

(.197)

$.559^{* *}$

(.163)

$.774^{* * *}$

(.152)

$.562^{* *}$

(.178)

$.809^{* * * *}$

$.614^{* * *}$

(.161)

$-.586$

(.170)

$-.500$

(.371)

$-.583$

(.378)

$.196^{* *}$

(.357)

$.207^{* * *}$

(.061)

(.063)

$.196^{*}$

(.066)

Standard errors clustered by county (14 clusters), ${ }^{* * *} \mathrm{p}<.001, * * \mathrm{p}<.01, * \mathrm{p}<.05$

\begin{tabular}{ccc}
$-.014^{* *}$ & $-.014^{* *}$ & $-.014^{* *}$ \\
$(.004)$ & $(.004)$ & $(.004)$ \\
.0005 & $.0006^{*}$ & $.0006^{*}$ \\
$(.0002)$ & $(.0002)$ & $(.0002)$ \\
-.011 & -.014 & -.015 \\
$(.026)$ & $(.033)$ & $(.034)$ \\
$9.771^{* * *}$ & $9.758^{* * *}$ & $9.763^{* * *}$ \\
$(.348)$ & $(.352)$ & $(.349)$ \\
\hline .3804 & .4242 & .4277 \\
\hline
\end{tabular}

$.834^{*}$

(.301)

(.285)

(.304)

.014

(.168)

(.165)

$-.109$

(.213)

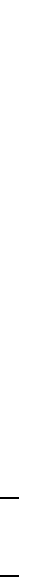




\section{Table 4. Summary of hypotheses and findings}

\section{Hypothesis}

1 Pantries that prioritize meeting the hunger needs of their communities will provide a higher service level than those that do not.

2 Pantries that prioritize the faith and/or values expression of their staff, volunteers, and donors will provide a lower service level than those that do not.

A We expect a relationship between pantries that prioritize the faith and/or values expression of their staff and volunteers and service levels, but the direction is unclear.

B We expect a relationship between pantries that prioritize the faith and/or values expression of their donors and service levels, but the direction is unclear.

3 Pantries that prioritize cost efficient services will provide higher service levels than those that do not.

4 Pantries that prioritize developing and sharing new service strategies will provide higher service levels than those that do not.

5 Pantries that prioritize providing high-quality services will provide lower service levels than those that do not.

6 Pantries involved in government-partnering or public sector engagement will provide higher service levels than those that do not

$\begin{array}{cc}\begin{array}{c}\text { Predicted } \\ \text { relationship }\end{array} & \text { Result } \\ \text { Positive } & \text { Supported } \\ \text { Negative } & \text { Not supported } \\ \text { Unknown } & \text { Mixed result } \\ \text { Unknown } & \text { Negative } \\ \text { Positive } & \text { Supported } \\ \text { Positive } & \text { Supported } \\ \text { Negative } & \text { Not supported }\end{array}$

Positive Supported 